"A MINHA APRENDIZAGEM DOS SERES SUPOSTOS/ VIVOS": UMA LEITURA DE NOVAS VISÕES DO PASSADO, DE FIAMA HASSE PAIS BRANDÃO

\author{
“MY LEARNING OF THE BEINGS \\ SUPPOSED TO BE/ ALIVE": A READING OF \\ NOVAS VISÕES DO PASSADO, \\ BY FIAMA HASSE PAIS BRANDÃO
}

Aderaldo Ferreira de Souza Filho*

\begin{abstract}
RESUMO
Neste estudo, apresentamos uma leitura de Novas visões do passado, de Fiama Hasse Pais Brandão, em que se procura analisar um novo conceito-tema que ali surge, o de figura, e que acompanhará o restante do percurso da autora. Conceito que envolve a noção e efetuação do simulacro, em sua potência afirmativa, insistindo sob a representação. Procuramos assim avaliar como ele integra as imagens, as reflexões metapoéticas e os procedimentos de escrita no livro.
\end{abstract}

PALAVRAS-CHAVE: figura; simulacro; Fiama Hasse Pais Brandão; Poesia portuguesa contemporânea

\title{
ABSTRACT
}

The following article presents a Reading of Novas visões do passado, by Fiama Hasse Pais Brandão, where the theme/concept of figura, which will be present throughout the following books of the author, is analyzed. This theme/concept comprehends the simulacrum in its affirmative power, persisting under the representation. Therefore, this work tries to show how it articulates the poetic images, the metapoetics reflexions and the writing proceedings in Novas visões do passado.

KEYWORDS: figura; simulacrum; Fiama Hasse Pais Brandão, contemporary portuguese literature. 


\section{VER GNOMOS}

Novas visões do passado (1975) apresenta-se como ponto de viragem no percurso poético de Fiama. Ali encontramos já o atenuamento de uma dicção elíptica que predomina nos primeiros livros, marcada por profundos cortes sintáticos, experimentação que não deixará de se manifestar em sua obra posterior, sobretudo em Melómana (1978), mas que é ultrapassada por uma tendência maior a uma linguagem mais límpida, afirmada sobretudo em Cantos do canto (1995) e Cenas vivas (2000). Ainda, perfaz-se uma reflexão crítica sobre os postulados iniciais de sua poesia, que será constante ao longo da Obra breve, e, sobretudo, a apresentação de um novo conceito de imagem ou figura que, apesar de numa leitura retrospectiva podermos dele encontrar indícios ou sugestões em poemas anteriores, assume aqui uma dimensão central, teoricamente elaborada, e configura-se como tema do livro - a novidade da visão incide não apenas sobre o passado histórico, mas também profundamente sobre a escrita passada da autora. Essa teorização sobre as novas visões que sua poesia vislumbra, essa encenação da descoberta das figuras, será retomada e aprofundada em Área branca (1979), tal a sua importância no desdobramento do projeto poético da autora. Nesse estudo, procedemos a uma leitura do tema das figuras em Novas visões do passado, remetendo brevemente a seus desdobramentos em Área branca.

Leiamos o poema que abre Novas visões do passado:

\section{O gnomo}

Estar aqui, onde for, ver as folhas de palma é como figurar em naturezas mortas. Rãs, se existem, são estas. Coaxa, rã, que eu nunca ouvira na margem do rio precedente. Recapitulo a minha aprendizagem dos seres supostos vivos, tal como o parágrafo de um grilo, as insistências. De max reinhardt recebi, mais uma vez, a realidade; as imagens instituídas para a relação com o irreal, o das imagens que inovam. E, ainda, o terceiro termo de ambos, o fantástico, o irreal histórico.

É de ouro a pele húmida mítica da sapiência da fábula e da ignorância. Poderia este gnomo, na eterna mudança, depois da metamorfose, ter o dom bovino. Coaxa, para além do nome, anfíbio! Dilata a pele, passa, de ser lacustre, a habitante da erva, e deste a humano ou poeta, e deste à imagem fabulosa. Mudada, eu já vivia em sistemas de símbolos. Tinha as visões do rio, no entanto vejo-as. Agora eis o pinho e a palma. É um jardim antigo, era a vontade de imaginar, nesse século, e a colocação do vento, igualmente, para a visão mirífica. (BRANDÃO, 2006, p. 197)

O poema, não sem certa ironia, sugere a visão de um ser inexis- 
tente, um gnomo. Segundo o Dicionário dos símbolos de Chevalier e Gheerbrant, esses são seres que, além de habitar o interior da terra e guardar tesouros e metais preciosos,

Simbolizariam o ser invisível, e que, pela inspiração, intuição, imaginação e sonho, tornariam visíveis os objetos invisíveis. Eles são, na alma humana, como que lampejos de conhecimentos, de iluminação e de revelação. São como que a alma escondida das coisas, orgânicas ou não, e quando se retiram, as coisas morrem, tornam-se inertes e tenebrosas. (CHEVALIER, GHEERBRANT, 1997, p.35)

Em Notas al texto de Concierto Barroco, Alejo Carpentier especula sobre uma confusa etimologia do termo que para alguns vem do grego genomas, "terrestres", e para outros, do verbo gnomai, "conhecer" (cf. CARPENTIER, 2011, p. 297). As duas possibilidades são sugestivas para as imagens da poesia de Fiama. Tornar visível o invisível e, paralelamente, tornar invisíveis, obscuros, ambíguos, "herméticos", os referenciais mais imediatos de uma visão, assim como sua imagem biográfica no texto, se tornará um dos processos mais característicos de sua poesia. O poema, que o põe em prática, inicia-se com a contemplação de uma paisagem (real?) e a sobreposição de figuras imaginadas. Figura-se sobre uma "natureza morta", rãs que tornam-se gnomos, e que dão vida à paisagem, à imagem estática. Tais figuras encontram-se sob o modo da suspeita, da suposição: "rãs, se existem,/ são estas", "seres supostos/ vivos". A quebra do verso aqui redobra a ambiguidade: seres suspeitos de existirem, seres de uma vitalidade suposta. Suspeita que, no entanto, ao longo da poesia de Fiama tem o tom progressivamente modulado para a afirmação: "Não é tão estranha a vitalidade da Natureza/ quando as paisagens são cópias// quanto é estranha e simples sempre/ que a humanidade as considera reais"; "dois camponeses efêmeros/ me pagaram a pouca água real/ que quebra o enigma das imagens", lemos em Área branca e Cenas vivas. (BRANDÃO, 2006, p. 280 e p. 610) A paisagem inicial da visão, em "O gnomo", as folhas de palma, recai sob a indecidibilidade do referencial, "Agora eis o uno/ e o exótico, o pinho e a palma”. A palmeira figurará ainda no importante poema de abertura de $\mathrm{Ho}$ menagemàliteratura, intitulado "Asas malignas", em que o processo de sobreimpressão de imagens é aprofundado. Assim, uma profusão de imagens nos afasta de uma referencialidade primeira, de uma origem, e nos instala diretamente em um lugar outro, indeterminado: "Aqui, seja onde for".

O gnomo figura como um tipo de imagem muito específico: não o real, mesmo esse sendo definido a partir do teatro, da dramaturgia ou encenação, "De max reinahrdt recebi, mais uma vez, a realidade", tampouco pura e simplesmente o seu arquétipo cultural, o "fantástico, irreal históri$\mathrm{Co}^{\prime 2}$, que lhe serve de "imagem provisória" (título de um outro poema do livro). Trata-se de uma nova visão, que não remete a um referente apreensível totalmente por nominação, nem a uma imagem cultural herdada por nosso imaginário, mas que, contudo, insiste sob a representação: "vivos tal 
como o parágrafo de um grilo, as insistências". Por isso, ao mesmo tempo o vemos e não vemos, "sapiência da fábula e da ignorância", apreensível somente a partir de sua atualização sob a profusão de máscaras - rã, boi, poeta: "Poderia este gnomo, na eterna mudança,/ depois da metamorfose, ter o dom bovino./ Coaxa para além do nome, anfíbio!/ Dilata a pele, passa, de ser lacustre, a habitante da erva,/ e deste a humano ou poeta, e deste à imagem fabulosa./ Mudada..." A figura ou simulacro deve coaxar "para além do nome", fugindo à designação. Ressalta-se aqui a ironia frente à situação encenada, o ver gnomos: "dom bovino", onde um ouvido piedoso percebesse talvez "dom divino". O simulacro e sua potência metamórfica, em Fiama, são dons da terra.

"Mudada". As transformações pelas quais passa o gnomo-simulacro são inseparáveis de um devir-figura de quem escreve e contempla, teoriza (em Fiama, é sempre importante lembrar que teoria, em sua raiz grega, significa ver, contemplar). Em Área branca, leremos: "Sei que me tornei nada./ Os filhos da Natureza podem ver-me/ mas não comprovam a minha realidade”. (BRANDÃO, 2006, p. 317) Fiama, a rã e o gnomo confundem-se, e a ironia para com a noção de real que o poema desloca e problematiza desdobra-se numa autoironia mais profunda. "Coaxa”, o imperativo que se repete, significativamente, recai também sobre a imagem da poeta. Sabemos que, em Área branca, a rã será uma das principais imagens sob as quais Fiama se apresenta, "o poema me rodeou subitamente/ para me expulsar da minha forma latente/ de batráquio". (idem, p. 315) Neste mesmo livro, a cena da visão da figura da rã (do gnomo?) é retomada, sob o modo da contemplação do incognoscível: "A sufocação dos significados/ até a atrocidade de ouvir rãs/ não sabendo o que são, se eu descresse/ de toda a figura verde-terra”. (ibidem, p. 293, grifos nossos) Ainda, Fiama retoma a imagem das rãs em Cenas vivas, no poema "A voz da rã", em que se exerce uma aguda ironia em relação a sua recepção pela crítica (note-se que o poema se insere na seção "Louvores"): “Os críticos, porém, raça de leitores, o Verbo os bendiga,/ sem olharem em si a razão intimíssima,/ viram as minhas sílabas mutiladas/ como a miséria do amor de quem vãmente ama” (ibidem, p. 654).

A autoironia que se desdobra, aqui, na encenação do vislumbre de um gnomo no jardim, remete, no entanto, também à reavaliação de seu percurso poético até o momento: "recapitulo a minha aprendizagem". O imperativo "coaxa" marca, em princípio, a necessidade de que o ser suposto vivo dê algum sinal de presença, pois "nunca [o] ouvira/ na margem do rio precedente" (grifos nossos). Recapitula-se aqui "Grafia I" e as imagens do rio disseminadas por Morfismos (1961).

Água significa ave

a sílaba é uma pedra álgida

sobre o equilíbrio dos olhos 
as palavras são densas de sangue

e despem objectos

se

o tamanho deste vento é um triângulo na água

o tamanho da ave é um rio demorado

onde

mãos derrubam arestas

a palavra principia (idem, p.15)

Em "Grafia I" via-se apenas a ave sobre o rio, mas não se ouvira ainda a rã. São questões diametralmente opostas as levantadas pelos dois poemas, sob signo dos dois animais. Em "Grafia I", trata-se da afirmação do poder da palavra sobre o fluxo do tempo ou das aparências: "se// o tamanho deste vento é um triangulo na água/ o tamanho da ave é um rio demorado". A palavra, a significação, "Água significa ave”, a nominação, se afirmam como forma de habitação ("rio demorado"), de retensão do fluxo de imagens mutantes que perpassam sobre a água - e o tempo, evidentemente -, tema da habitação que Fiama explorará em toda a sua poesia. Em "O gnomo", trata-se da afirmação da vitalidade do fluxo subjacente que escapa à palavra, à forma ("triangulo"), à representação em geral. Afirmação do simulacro que perturba a representação e que, de sua perspectiva, não conforma uma realidade, por tornar a referenciação ambígua e, mais profundamente, indecidível.

Ao recapitular o aprendizado, Fiama não está, contudo, simplesmente assumindo uma posição que entra em contradição com o início de seu percurso. Se os poemas, tomados em si, apresentam perspectivas aparentemente opostas, outras imagens de Morfismos, no entanto, já apontam para os desdobramentos posteriores: "Limítrofes/ os nossos pés anfíbios/ invocam o rio" (idem, p. 18). As duas perspectivas apontadas se complementam, não em uma síntese, mas em uma modulação que movimenta suas reflexões posteriores, sua suspeita sobre a metáfora e a palavra ${ }^{3}$. Sendo essa, em seu desenvolvimento progressivo, uma poética de afirmação do simulacro, das potências do falso, de clara inspiração nietzschiana ${ }^{4}$, é impossível não pensarmos aqui nos animais de Zaratustra, no espelhamento da ave e da rã de Fiama em suas águia e serpente. Assim, não há contradição entre a postura inicial e a nova visão, nem mesmo uma contradição resolvida numa síntese dialética. A contradição é sisuda, remete ao trabalho do negativo, ao "espírito de gravidade", diria Nietzsche. "Nada se opõe, tudo difere" (ibidem, p. 192), lemos num dos últimos poemas de Novas visões do passado. Em lugar da seriedade da contradição, Fiama nos apresenta o humor do paradoxo: "Tinha visões do rio, no entanto vejo-as". 
Autoironia na recapitulação: é também a si própria que Fiama diz “Coaxa, para além do nome, anfíbio!”. Fugir ao princípio de identidade do nome, tanto vale para o gnomo-rã, a nova visão que passa a figurar nos poemas, como para a poeta, em seu hermetismo biográfico:

Como um paradigma entrego eu a outros a forma como passou o tempo enquanto o dia se fez noite, tons de cinzento desapareciam e eu me tornava tão incorpórea para sempre. Mesmo em minha vida o meu texto se distinguia do meu corpo e era por mim legado à decifração. (idem, p. 190)

A questão não deixa de ser a da "forma como passou o tempo", ou seja, "um triângulo na água", no rio do tempo, mas, a partir da recapitulação, implica também a consciência e a efetuação de um irreversível devir-figura, "eu me tornava tão incorpórea/ para sempre". Poderíamos dizer, como Deleuze e Guattari, um devir-imperceptível ou anônimo, se soubermos que este não implica necessariamente tornar-se invisível, mas em uma tendência que nos instala nos limiares da percepção, do representável, fugindo às significações dominantes. Esse devir-figura estará relacionado, ao longo de sua poética, com a temática da solidão, tanto íntima, como a de uma postura de distanciamento crítico frente às relações públicas, a um uso instrumental da linguagem. "Hoje defino-me como ente/ só" e "Falar da solidão insistente [...] o homem retira daí a lira para a cena,/ cria à semelhança dos herdeiros dos cantos/ órficos cantos permanentes, entre esses seres sós", lemos em dois outros poemas de Novas visões do passado (ibidem, p. 187 e p. 182-3). Ente só, entre seres sós, em sua "marginalidade,/ situação na margem” (ibidem, p. 187), margem da representação, margem do rio, contemplando, teorizando. Como diria Bandeira, "sapo-cururu/ da beira do rio...":

\section{Os sapos}

Enfunando os papos,

Saem da penumbra,

Aos pulos, os sapos.

A luz os deslumbra.

Em ronco que a terra,

Berra o sapo-boi:

— "Meu pai foi à guerra!"

- "Não foi!" - "Foi!" - "Não foi!"

O sapo-tanoeiro

Parnasiano aguado,

Diz: - "Meu cancioneiro

É bem martelado.

Vede como primo

Em comer os hiatos!

Que arte! E nunca rimo

Os termos cognatos.

$\mathrm{O}$ meu verso é bom

Frumento sem joio.

Faço rimas com 
Consoantes de apoio.

Vai por cinquenta anos

Que lhes dei a norma:

Reduzi sem danos

A fôrmas a forma.

Clame a saparia

Em críticas céticas:

Não há mais poesia,

Mas há artes poéticas...”

Urra o sapo-boi:

- "Meu pai foi rei" - "Foi!"

— "Não foi!" - "Foi!" - "Não foi!"

Brada em um assomo

O sapo-tanoeiro:

— "A grande arte é como

Lavor de joalheiro.

Ou bem de estatutário.

Tudo quanto é belo,

Tudo quanto é vário,

Canta no martelo."

Outros, sapos-pipas

(Um mal em si cabe),

Falam pelas tripas:

-“Sei!” - "Não sabe!” - "Sabe!"

Longe dessa grita,

Lá onde mais densa

A noite infinita

Verte a sombra imensa;

Lá, fugido ao mundo,

Sem glória, sem fé,

No perau profundo

E solitário é

Que soluças tu,

Transido de frio,

Sapo-cururu

Da beira do rio... (BANDEIRA, 2007, p. 60-2)

Não há, contudo, identificação fácil entre os sapos de Manuel Bandeira, tanto os parnasianos tagarelas como o sapo-cururu retirado à margem, e a máscara de batráquio sob a qual Fiama se nos apresenta. Em princípio, pode-se pensar num paralelo entre a crítica de Bandeira aos altissonantes e repetitivos sapos que "reduz $[\mathrm{em}] \mathrm{sem}$ danos/ a fôrmas a forma", que bradam que "tudo quanto é belo,/ tudo quanto é vário,/ canta no martelo" e a autocrítica e autoironia a que Fiama se impõe na recapitulação de seu aprendizado. Num contexto evidentemente diferente, mas de certa forma análogo, Bandeira está preocupado em liberar o verso livre dos rigores das formas fixas, Fiama, em liberar os simulacros, as imagens livres, das formas-imagens fixas, do nome, da ave ou do triângulo que estabiliza a variação do rio. 
Em Bandeira, no entanto, há uma oposição clara entre dois pensamentos e posturas distintos: enquanto parnasianos bradam e urram, um sapo se retira para a noite mais densa, com uma dicção menor, a do soluço. Em Fiama, a contemplação das figuras que escapam ao domínio da palavra e da representação também implica uma postura de afastamento: "Fito-os porque se transformam [...] A minha persistência no litoral. Ignoro, mas contemplo" (BRANDÃO, 2006, p. 189) - assim se inicia e conclui um poema sem título de Novas visões do passado. Há uma expectativa de silêncio, de abandono da palavra que é aqui implícita, como lemos em outro poema: "esclareço/ que me vieste libertar da apropriação das coisas próprias,/ da atribuição dos denominadores às coisas, da técnica/ flagrante da meditação" (idem, p. 193). Talvez se sugerisse aqui a tentação de seguir o famoso conselho de Witgenstein segundo o qual aquilo de que não se pode falar deve permanecer em silêncio.

E, no entanto, o imperativo que se repete é o de coaxar, “Coaxa, rã [...] Coaxa, [...] anfíbio!", viver entre as figuras é também “viv[er] em sistemas de símbolos", como lemos em "O Gnomo", ou ainda, noutro poema do livro: "Não serei volúvel a ponto de me despedir de símbolos" (idem, p. 189). Em lugar de uma dicção próxima do silêncio, e longe de afirmar uma oposição fácil entre uma poética apolínea, da medida, e outra dionisíaca, do excesso, Fiama, estabelecendo uma aliança entre ave e rã, descobre uma nova potência da repetição, sob a ecolalia dos sapos de Bandeira que repetem formas: "Urra o sapo-boi: / - "Meu pai foi rei!”- "Foi!”/ - “Não foi!" "Foi!" - "Não foi!". A ideia de repetição (assim como a de diferença) aparece constantemente em Novas visões do passado, funcionando como conceito: "recapitulo", "Os contornos numa noite, repetiam-se, eram o idêntico" (ibidem, p. 180), "repetição no horizonte do mármore da cantaria" (ibidem, p. 182), "Eu própria repetirei que há um fundo possível fictício/ ao encontro da aglomeração das árvores" (ibidem, p. 185), além da imagem da repetição no trabalho de Penélope, que veremos adiante. Ecolalia. É ainda sob o signo da ninfa Eco que Fiama se põe no convívio com as figuras, como demonstra um poema em que o sujeito lírico se instala dentro das imagens que contempla em gravuras, processo característico da autora: "Durmo no poente balcânico das gravuras./ Convivo com tudo que é corpóreo/ [...]/ Foi Eco, corpo, que deslocou os meus pés/ para além da terra”. A ninfa Eco possuía o dom da palavra. Por utilizá-lo para distrair Hera enquanto Zeus cometia seus famigerados adultérios, a ninfa foi condenada a poder apenas repetir o final das frases que seus interlocutores lhe dirigiam. O coaxar de Fiama, gagueira da linguagem, inserido entre uma repetição do passado, da tradição, e insistência das novas visões ${ }^{5}$ tal como o gnomo, a rã: "Resumo a fatalidade das letras, o destino dos enunciados,/ as variações que introduzo”. (ibidem, p. 186) Rosa Maria Martelo, em O cinema da poesia, sugere a importância do procedimento repetitivo das imagens em Fiama: 
A obra de Fiama dá-nos uma das mais elaboradas meditações sobre a relação entre poesia e imagem de toda a história da poesia portuguesa. Seria impossível resumir aqui toda a sua complexidade, no entanto, lembrarei que a poeta reconhece na natureza o dom de replicar as imagens - a forma das andorinhas em novas andorinhas, por exemplo -, ao mesmo tempo que observa na poesia essa mesma capacidade de re-fazer na diferença. (MARTELO, 2012, p. 129)

Potência da repetição que produz a diferença, o simulacro sem imagem, que desliza sob elas, insistindo. Uma profunda reflexão sobre a ideia de repetição se desdobra se acompanharmos o anseio teórico de Fiama ao longo dos poemas. Por ora, voltaremos a atenção para como as figuras-simulacros aparecem em Novas visões do passado, apenas sublinhando alguns dos traços do procedimento de repetição que será abordado futuramente noutro artigo.

\section{"FITO-OS PORQUE SE TRANSFORMAM. [...] IGNORO, MAS CONTEMPLO."}

As figuras, em Novas visões do passado, mais do que como projeção do imaginário sobre a paisagem, que é o seu modo efêmero de presença, seu jogo de máscaras, se apresentam sob o modo do desconhecido, do mistério, insistindo sob as representações. "Não há um sono íntimo/ nem exterior, só a presença e a ausência de cada ser” BRANDÃO, 2006, p. 180). Lemos ainda em alguns versos de "Organista": "Os emblemas mortais,/ foice e gadanha, representam./ O desconhecido ou alguém configura o homem,/ ecce, não cógnito, em figura" (idem, p.180). Figuras que são um fundo vital que escapa à representação, aqui claramente associada à morte, "foice e gadanha". Tal como o gnomo: "seres supostos/ vivos" "figura[dos] em naturezas mortas". Mais uma vez, em lugar de uma dialética do visível e do invisível, Fiama nos sugere a insistência do paradoxo: "ecce, não cógnito, em figura". Vejamos agora um dos exemplos daquilo que o poema de abertura nos sugere por "sapiência da fábula e da ignorância":

\section{A tecelagem}

No dia em que regressou à ilha de Ítaca o sol

tudo se mudara, embora a tecelagem deliberadamente simbólica

fosse, por exagero, interminável. Na verdade, não só isso mas tudo tendia a ser outro. Havia chovido brandamente na véspera entre as proas. $\mathrm{O}$ raio brusco repentino intenso colorira de novo tom muralhas. Supunha que na cidade alguém ainda entrara como cidadão e recebera todo o direito da cidadania. Dando à população a figura, habituando-nos ao desconhecido. Hoje, ela esplende ao tear. Ontem nem a tecelã, ninguém e nada haviam podido furtar-se ao início do fim. (idem, p. 182) 
Estamos diante de imagens da repetição, a tecelagem de Penélope, desfeita a cada noite e retomada a cada manhã, o retorno regrado do ciclo solar, o regresso de Ulisses. O poema que precede "A tecelagem" já nos antecipa o tema, ao encerrar com “(...) ria repetição no mármore da cantaria" (idem, p.182) e três poemas antes temos a imagem da ninfa Eco. Num primeiro plano, quem regressa a Ítaca não é propriamente o rei navegante, mas o sol, após um dia de chuvas. Regressa à maneira de um encoberto. Penélope "esplende ao tear", e também Fiama, como sugerem esses versos dois poemas adiante: "Estou atenta/ ao tecido da minha vida. Não é simbologia/ o facto literal de eu assumir, no descolorido do sol,/ irisação da teia, a minha vida como o fiar" (ibidem, p. 183). Entretanto, é necessário estar atento à homofonia (repetição abarcando uma diferença) que pode nos levar a ler vida como fiar. Dirá a poeta adiante, "Exigi diferenças minuciosas" (ibidem, p. 190). Assume-se a representação, a encenação e também aquilo que lhe escapa, a vida, biografia hermética, vitalidade do simulacro. E lembremos aqui Jorge Fernandes da Silveira, num ensaio já clássico, "Alta costura: 'A Roupa' de Fiama”, a apontar a importância da imagem da tecedora, e do tecido, evidentemente, comentando um outro poema, o de número 10 em Área branca, em que,

por meio da metáfora do ofício resignado da tecedora, há uma ardorosa interpretação do literário como agente da passagem entre o mítico e o histórico. [...] Para Fiama Hasse Pais Brandão - a tecedora e sua figura, ela mesma -, há limites na trama de simulacros que enreda o poeta nesse jogo de fingimento e verdade. (SILVEIRA, 2006, p. 176-7) ${ }^{6}$

Como sugere "A tecelagem", a verdadeira vida das imagens do tear se faz na ausência do sol, quando Penélope, segundo o mito, o desfaz, "no descolorido do sol,/ irisação da teia". O regresso do sol, no poema "A tecelagem", prepara a chegada de Ulisses, numa amanhã esplendorosa como a tecedora: "O raio brusco/ repentino intenso colorira de novo tom/ muralhas". O sol promove a mudança do tempo, também climático, e aguarda que a chegada do rei seja o restabelecimento da ordem, a conclusão de um ciclo. Fiama, no entanto, nos propõe uma leitura do mito sob outra perspectiva. O sol "Supunha que na cidade alguém/ ainda entrara como cidadão e recebera todo o direito/ da cidadania. Dando a população a figura,/ habituando-nos ao desconhecido". A suposição é entretanto frustrada. Os simulacros, as figuras, os "seres supostos", não são apreensíveis pelo reconhecimento. A luz solar, visão apolínea, não nos revela Ulisses, e este tampouco dá “à população a figura,/ habituando-nos ao desconhecido". Ulisses chega a Ítaca disfarçado de mendigo, como simulacro, phármakon, interrompendo a repetição bruta do idêntico na representação ao tear.

O sol aparece aqui como vítima da astúcia de Odisseu, tal como os pretendentes de Penélope. Mais profundamente, como um pretendente à clareza da representação, procura presidir a restauração da ordem. E Ulisses por sua vez traz a mudança (ao contrário de como o mito aparece 
em Homero, em que o rei restabelece a ordem em Ítaca), vem como uma nova visão, introduzindo uma alteração mais profunda que a do sol que "colorira de novo tom/ muralhas", pois "nem a tecelã, ninguém e nada/ haviam podido furtar-se ao início do fim". Marca-se a oposição entre um devir racionalizado, cíclico, previsível, mediado, dialético e outro que remete a uma irrupção insidiosa do simulacro, imprevisível. "Encontro inesperado do diverso", como em Llansol. Ulisses também regressará em Área branca, como mestre dos simulacros:

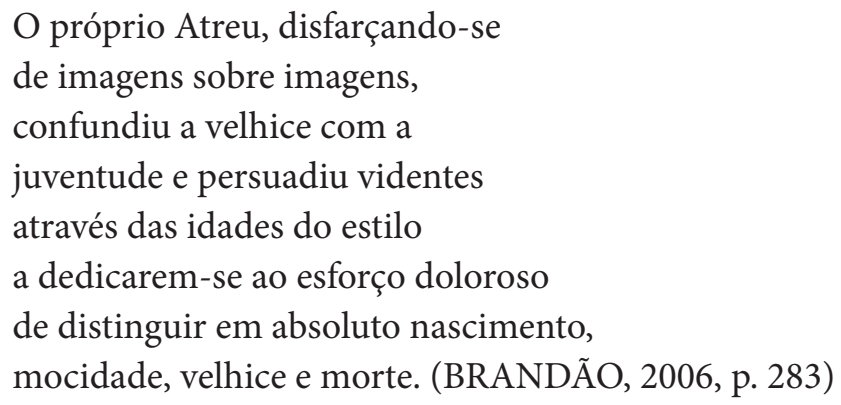

Trata-se de um poema, de número 4 em Área branca, em que a questão dos simulacros aparece profundamente associada às questões políticas que atravessam a obra de Fiama. Não podemos analisá-lo aqui devido a sua extensão e complexidade, deixamos apenas um excerto em nota ${ }^{7}$ para retornar à figura de Ulisses em "A tecelagem".

Fiama insiste sobre a questão civil ou política (pólis, cidade): "Supunha que na cidade/ alguém ainda entrara como cidadão e recebera todo o direito/ de cidadania”. A redundância e a tautologia não são gratuitas, estão relacionadas à suposição do sol que pretende dar a ver o Mesmo, o reconhecível, que procura capturar o simulacro identificando-se a ele, fazendo com que o seu regresso ("no dia em que regressou a ilha de Ítaca o sol”) coincida com o seu, em uma repetição que anule a diferença. É à crítica da ideia de cidadania que devemos aqui atentar, tal como se desenvolve em outros poemas de Novas visões do passado. Em "O campesinato e o operariado", segundo poema do livro, lemos: "Ninguém necessita de um país/ político, mas só dum país de pura diversificação" (BRANDÃO, 2006 , p. 178). Fiama aqui chama a atenção para os perigos da representatividade política que, sob o regime do reconhecimento e da identidade, sempre ameaça suprimir a singularidade dos indivíduos. "O progresso não é desejar uma pátria materna, mas a abolição/ deste arquétipo ou símbolo, assim como o de um país uno/ como tradução da unicidade de cada indivíduo nele,/ carente ou homogénea" (idem, p.178). A fuga às identificações, para além de um procedimento exclusivamente linguístico, converge diretamente com o pensamento político que Fiama desenvolve em sua escrita.

Se, no entanto, a repetição aparece aqui como uma potência ordenadora e representativa - solar, apolínea - reprodução da identidade através de ciclos, devemos, pois, distinguir, como propõe Gilles Deleuze em Diferença e Repetição, a repetição bruta do mesmo, e a repetição como diferença: 
A primeira repetição é a representação do mesmo e explica-se pela identidade do conceito ou da representação; a segunda é a que compreende a diferença na alteridade da Ideia, na heterogeneidade de uma "apresentação". [...] Uma é desenvolvida, explicada, a outra é envolvida, devendo ser interpretada. Uma é revolutiva, a outra é evolutiva. Uma é de igualdade, comensurabilidade, simetria, a outra funda-se no desigual, no incomensurável ou no dissimétrico. Uma é material, a outra é espiritual, mesmo na natureza e na terra. Uma é inanimada, a outra tem o segredo de nossos mortos e de nossas vidas, dos nossos aprisionamentos e libertações, do demoníaco e do divino. Uma é a repetição "nua", a outra é a repetição vestida, que se forma a si própria vestindo-se, mascarando-se, disfarçando-se. Uma é de exatidão, a outra tem a autenticidade por critério. (DELEUZE, 2000, p. 74-5)

Ao recapitular seu aprendizado das figuras, Fiama retoma as linhas de força já presentes em sua poética sobre uma nova dimensão, elaborando a ideia de figura que se desdobrará em suas obras posteriores. Como pudemos acompanhar, a figura, a afirmação da potência do simulacro, será essencial nos procedimentos que sua aventura poética desenvolve: retomada insistente de imagens dos seus poemas anteriores (repetição diferida destes Ulisses ou sapos “mascarados”), o diálogo com a tradição (Lápide \& Versão como exemplarmente ensina Jorge Fernandes da Silveira), a configuração de uma biografia hermética que se confunde com um devir-figura, e todo um posicionamento político que implica uma reflexão sobre as tensões entre a representação e os elementos que lhe escapam, lhe perturbam, insistindo.

\section{REFERÊNCIAS BIBLIOGRÁFICAS}

BANDEIRA, Manuel. Estrela da vida inteira. Rio de Janeiro: Nova Fronteira, 2007.

BRANDÃO, Fiama Hasse Pais. Obra breve. Lisboa: Assírio \& Alvim, 2006.

CARPENTIER, Alejo. Concierto barroco. Madrid: Akal, 2011.

CHEVALIER, Jean \& GHEERBRANT, Alain. Dicionário dos Símbolos. Porto: Círculo de leitores, 1997.

DELEUZE, Gilles. Diferença e Repetição. Lisboa: Relógio D’Água, 2000.

MARTELO, Rosa Maria. O cinema da poesia. Lisboa: Documenta, 2012.

SILVEIRA, Jorge Fernandes da. Alta costura: "A Roupa" de Fiama. In: Lápide \& Versão - Ensaios sobre Fiama Hasse Pais Brandão seguidos de Memorial da Pedra, Antologia poética. Rio de Janeiro: Bruxedo, 2006. 


\section{NOTAS}

* Doutorando na Universidade Federal Fluminense, Instituto de Letras, Programa de Pós-Graduação em Estudos de Literatura. Este trabalho foi elaborado no âmbito do projeto Poesia e Crítica na contemporaneidade CAPES/FCT, 2013-2015. Atualmente realiza doutorado sanduíche na Universidade Nova de Lisboa, como bolsista CAPES.

2 Essa distinção entre tipos de imagens é retomada no segundo poema de Área branca, que pode ser considerado como um prólogo teórico do livro. (Cf. BRANDÃO, 2006, p. 278-9)

3 "Depois de tantos séculos posso afirmar/ que a escrita é uma escravidão dura./ Sei que é inútil e desumano mover as mãos/ assim. Nem estou convicta de que seja digno/ escrever desta maneira (...)", "As figuras de estilística/ não são figuradas. De dentro/ da minha orelha posso extrair// a abelha dourada./ Mas não desejo/ sacrificar-me às metáforas" (BRANDÃO, 2006, pp. 298-9 e 314).

4 "Qual o lugar a próxima cidade ou linha fluida de um rio/ que seja mais do que a aparência de mover embora/ (nietzsche) essa beleza da aparência seja íntegra e/ movermo-nos possa ser a passagem (súbita) pelo momento mais feliz". "Em que lugar", poema de (Este) Rosto (1970). (BRANDÃO, 2006, p. 116)

5 Deleuze, em Diferença e repetição, define a repetição como "a diferença sem conceito" (cf. DELEUZE, 2006, p.74), o que, entre outras coisas, significa que é próprio do singular que não pode ser nomeado, representado, repetir-se sob máscaras, insistir.

$6 \mathrm{Na}$ perspectiva que aqui adotamos, o simulacro é propriamente a desmedida ou diferença que perturba os limites da representação. Se Jorge Fernandes da Silveira fala, por sua vez, de um limite, convém ressaltar que se trata, no seu texto, de uma medida ética, fulcral na obra de Fiama, que convém evidenciar para que não se confunda a questão propriamente moderna da potência do simulacro com algumas correntes representantes de um niilismo conformista, decorrente de sua incapacidade de pensar ética e politicamente novas formas de subjetividade: "aqueles que, ao arrepio da moda, industriados pela 'incipiência do poema', pregam a morte do sujeito poético e o fim das utopias" (SILVEIRA, 2006 p. 177).

7 "o poema, as barbatanas do dragão

que a literatura ainda assemelha

demasiadamente às da serpente,

tornam-se uma questão de raciocínio

ponderado, o que demonstra

que qualquer dos dados das palavras

sem suas normas de sentido

pode ser reflectido com vantagem

pela nova razão. Podem

os corpúsculos coloridos etéreos

que são as populações

sob o prisma das cores

passar ao novo futuro

como as fases da presença

absoluta incarnada na presença imaginária.

Era a sua vocação para a vida

que fora transformada

para o trabalho dos conceitos.

A vocação para as sensações

que fora alienada teologicamente

em força de trabalho. (BRANDÃO, 2006, p. 282) 